Mosul Journal of Nursing

www.mjn.mosuljournals.com

\title{
The Relation Between Stress Level and Nutritional Status Among Primary School Pupils in Mosul City
}

Article information

Article history:

Received May 14, 2019

Accepted August 26, 2019

Available online October 17, 2019

DOI: 10.33899/mjn.2019.163811 @2020, College of Nursing, University of Mosul.

Creative Commons Attribution 4.0 International License

Bayda A. Yahya ${ }^{1} \quad$ Tameem Thamir Mayouf ${ }^{2}$

Abstract

Background and Aim : Stress is now considered a common problem in children, it has been liked with both increased and decreased dietary intake. The study aimed to identify the relationship between stress level and nutritional status among primary school pupils in Mosul City.

Materials and Methods : A cross-sectional study has been designed for a sample of children consist of (200) pupils from the primary schools in Mosul City, aged (10-13) years old. The study has been conducted from $1^{\text {st }}$ of January to $30^{\text {th }}$ of April 2019. Data were collected through the interview of the children which included the height and weight measurement which done in the classroom and then the questionnaire about demographic characteristics, stress level and dietary intake were distributed for them to be answered by the one of child's parents. The data were analyzed through the application of descriptive statistical analysis that included frequency, percentage and Chi square .

Results : The study indicated that the $78.5 \%$ of the children were $10-12$ years old, $44.5 \%$ of them from moderate economic status, also show there are significant relationship between stress level and increase of weight, costumed saturated oils, meat, carbohydrate, low fruit and low vegetable intake at $\mathrm{P}$-value $=0.05$.

Conclusion : This study found consistent association between stress level and unhealthy dietary intake. Pupils with higher stress had higher consumption of fat and sugar which lead to obesity .

${ }^{1}$ Assistant Professor / College of Nursing / University of Mosul / Baedaaaabd@gamil.com .

${ }^{2}$ Assistant lecturer / College of Nursing / University of Mosul / Tameem.Thamir@uomosul.edu.iq 


\section{Mosul Journal of Nursing, Vol. 7, No. 2, 2019 ( 100-108 )}

Recommendations : Pay attention to the child by the family and school, reduce the psychological stress, he has by addressing his social problems and enhancing his selfconfidence .

Key words : Stress level, Nutritional status, Dietary intake, Obesity.

\section{Introduction}

Stress is defined as the body's physiological response as a result of pressures and events that overwhelm it and threaten and shake the person's ability to maintion balance (Torres and Nowson, 2007) .

Stress in the early stage of life has a negative impact on the development of the child, structure and function of the brain (Nelson, 2013; Charmandavi et al., 2003). Also its effect on physical activity, health behaviours, dietary intake and increasing risk of obesity (Nader et al., 2006 ; Telma et al., 2014) . Short -term stress can cause a people to lose their appetite, while longterm stress can lead to comfort eating which often involves the overeating of food that are rich of calories such as high fat and carbohydrates in an attempt to make them feel better (Sally, 2018; Honor, 2017) . Long time stress affects body functions and plays an important role in most of psychiatric disorders and indirect health behavior changes (Dohrenwend, 2006), One of the behavioral changes is food choice that affects health as a result of changes in appetite and dietary intake (Steptoe etal., 1998). Many people do not think about healthy eating at the time of stress, they often skip some meals especially the breakfast or eat fast food outside the home which can leads to more emotional strain and adversely affect their health (Canfield, 2011).

School-age children need a wellbalanced diet per day that is required to meet growth needs, as the child size increases (Edelman and Mandle, 1998), Over nutrition refers to an excessive intake of one or more nutrients which causes a stress on bodily function. Stress has been linked with high or low dietary intake (Geliebter and Aversa, 2003).

Obesity was considered a disease of stress (Tsenkova etal., 2013) . Excess of body weight is associated with many health problems such as heart disease, liver disease, high blood pressure, sleep apnea, gall bladder disease, depression, diabetes and endocrine disorders (Hurt, 2011).

The American Heart Association (AHA) , 2015 recommends limiting saturated fats which are found in butter, cheese, meat and fast foods, its can increase LDL -cholesterol and risk of heart disease. The increase in the frequency of eating meals (fast food and the snakes) away from home may be associated with the increase calories intake among children which lead to obesity (Davis etal., 2007). The low consumption of fruits and 


\section{Mosul Journal of Nursing, Vol. 7, No. 2, 2019 ( 100-108 )}

vegetable help the continuous increase in adiposity among children (Trichesa and Giuglianib, 2005). Higher consumption of carbohydrate is associated with higher calories intake, it has been estimated that every additional glass of a sweetened beverage drink per day by children increases becoming obese by $60 \%$ (Barnfather, 2004). The study aimed to identify the relation between stress level and nutritional status among primary school pupils in Mosul City. The purpose of this study was firstly, to find the relationship between the level of stress and the body mass index (BMI) for school pupils, second, to identify the association between stress level and dietary intake in the study sample.

\section{Materials and Methods}

A cross-sectional study design was carried out from $1^{\text {st }}$ of January to $30^{\text {th }}$ of April 2019 at primary schools in Mosul City. Prior to the actual collection of data formal administrative approval was obtained from Ninevah Directorate of Education, Planning Department to conduct this study. A sample consist of 200 pupils (100 male and 100 female) from a private and governmental primary schools in Mosul City. From each school two classes where selected (fifth and sixth class) and then we selected the sample randomly for each class. Data were collected through the interview of the children with help of their teacher, which include sociodemographic characteristics (age, gender, body mass index (BMI), socioeconomic level and mother education).

Anthropometric measures which adopted in the study include weight and height, for each pupil weight was measured by using electrical balance, height was measured by using vertical scale which done by the researchers in the classroom, then calculate the $\mathrm{BMI}=$ weight in kilograms over height in meters squared $\left(\mathrm{BMI}=\mathrm{wt} / \mathrm{ht}^{2}\right)(\mathrm{WHO}, 2000)$.

The questionnaire was distributed for each pupil in the classroom to be filled by one of their parents and to bring it back the next day.

The international scale were used for measuring the family socioeconomic status level (WHO, 1985).

The questionnaire also included about dietary intake saturated and unsaturated fats, grains, fruits, vegetables, meat and carbohydrate.

A global scale were used to measure stress level and its relation to student's dietary intake (WHO, 2017; Ollingrath etal., 2014) .

The data were analyzed through the application of descriptive statistical analysis that include (Frequency, Percentage and Chi Square). 
Mosul Journal of Nursing, Vol. 7, No. 2, 2019 ( 100-108 )

\section{Results}

Table (1) : Demographic Characteristics of the Study Sample N= 200

\begin{tabular}{|l|c|c||}
\hline Variables & Frequency & Percentage \\
\hline \hline Age & No. & \% \\
\hline \hline <10 years & 14 & 7 \\
\hline 10-12 years & 157 & 78.5 \\
\hline$\geq 13$ years & 29 & 14.5 \\
\hline \hline Gender & No. & $\%$ \\
\hline \hline Male & 100 & 50 \\
\hline Female & 100 & 50 \\
\hline \hline Body Mass Index (BMI) & No. & $\%$ \\
\hline \hline Underweight & 24 & 12 \\
\hline Normal & 87 & 43.5 \\
\hline Overweight & 51 & 25.5 \\
\hline Obese & 38 & 19 \\
\hline \hline Socioeconomic status & No. & $\%$ \\
\hline \hline Low & 49 & 24.5 \\
\hline Moderate & 89 & 44.5 \\
\hline High & 62 & 36 \\
\hline \hline Mother Education & No. & \% \\
\hline \hline Illiteracy & 53 & 8.5 \\
\hline Primary school & 88 & 21 \\
\hline Secondary school & & 26.5 \\
\hline College & 44 \\
\hline
\end{tabular}

This table shows that the most of the sample were (10-12) years old, they accounted 78.5 . 43.5 from study sample were normal weight , 44.5 of sample had an moderate economic level.

Table (2) : Stress level for pupils in relation with their BMI. No=200

\begin{tabular}{|l||c|c||c|c||c|c||c||}
\hline \multirow{2}{*}{$\begin{array}{l}\text { Body Mass } \\
\text { Index BMI }\end{array}$} & \multicolumn{2}{|c||}{ No stress } & \multicolumn{2}{|c||}{ Low stress } & \multicolumn{2}{|c|}{ High stress } & \multirow{2}{*}{ P- value } \\
\cline { 2 - 7 } & No. & $\%$ & No. & $\%$ & No. & $\%$ & \\
\hline \hline Underweight & 5 & 2.5 & 12 & 6 & 7 & 3.5 & 0.153 \\
\hline
\end{tabular}


Mosul Journal of Nursing, Vol. 7, No. 2, 2019 ( 100-108 )

\begin{tabular}{|c|c|c|c|c|c|c|c|}
\hline Normal & 49 & 24.5 & 22 & 11 & 16 & 8 & 0.527 \\
\hline Over weight & 12 & 6 & 22 & 11 & 17 & 8.5 & $0.031^{*}$ \\
\hline Obese & 3 & 1.5 & 14 & 7 & 21 & 10.5 & 0.014* \\
\hline Total & 69 & 34.5 & 70 & 35 & 61 & 30.5 & \\
\hline
\end{tabular}

* Significant

This table shows that there are significant relationship between stress level and increase of weight at $p$-value $=0.05$

Table (3) : Frequency and percentage of pupils regarding dietary intake. No. $=200$.

\begin{tabular}{|l|c|c||}
\hline Dietary intake & F & \% \\
\hline \hline Saturated fat & 98 & 49 \\
\hline Unsaturated fat & 102 & 51 \\
\hline Grains & 186 & 93 \\
\hline Fruits & 68 & 34 \\
\hline Vegetables & 78 & 39 \\
\hline Meat & 93 & 46.5 \\
\hline Carbohydrate & 126 & 63 \\
\hline
\end{tabular}

This table shows the majority of pupils (93\%) ate grains while the lowest number of them ate fruits $(34 \%)$.

Table (4) : The relation between Stress level for pupils and their dietary intake. No. $=$ 200

\begin{tabular}{|l|c|c|c|}
\hline \multirow{2}{*}{ Dietary intake } & \multicolumn{2}{|c|}{ Stress level } & \multirow{2}{*}{ P-value } \\
\cline { 2 - 4 } & Low stress & High stress & \\
\hline \hline Global Dietary Index & $0.72 \pm 0.31$ & $0.83 \pm 0.25$ & 0.001 \\
\hline Saturated fat & $6.2 \pm 5.5$ & $8.7 \pm 6.1$ & $0.021^{*}$ \\
\hline Unsaturated fat & $4.3 \pm 3.1$ & $4.3 \pm 3.1$ & 0.055 \\
\hline Grains & $14.6 \pm 5.3$ & $11.3 \pm 5.0$ & 0.051 \\
\hline Low fruits intake & $3.8 \pm 2.4$ & $5.3 \pm 3.1$ & $0.000^{* *}$ \\
\hline Low vegetables intake & $6.3 \pm 3.3$ & $6.1 \pm 3.5$ & $0.03 *$ \\
\hline Meat & $15.1 \pm 6.2$ & $15.6 \pm 6.7$ & $0.000^{* *}$ \\
\hline Carbohydrate & $27.5 \pm 9.3$ & $23.9 \pm 7.5$ & $0.01 *$ \\
\hline
\end{tabular}

* Significant

** High significant 


\section{Mosul Journal of Nursing, Vol. 7, No. 2, 2019 ( 100-108 )}

This table shows that there are significant relationship between stress level and pupils who ate saturated fat, meat,

\section{Discussion}

The results of the study in table (1) showed that $78.5 \%$ of the children were $10-12$ years old, $43.5 \%$ of them were are normal body mass index and $44.5 \%$ of them were moderate economic level.

Our finding at table (2) show that $25.5 \%$ of the children had overweight and 19\% had obesity. Yahya et al., (2005) found there was no significant difference between the nutritional status of pupils and economic status, while there was a significant increase in cases of overweight for pupils in moderate economic status, in addition, overweight was diagnostic at $7.5 \%$ of students.

Table (2) also shows that there are significant relationship between stress level and increases of BMI for pupils, overweight $\mathrm{p}=0.031$ while obese $\mathrm{p}=0.014$ at $p$-value $=0.05$, we identified that stress affect on development of obesity. A finding in this study is agreement with Tsenkova et al. (2013), Moore and Cunningham (2012) and Tamashiro (2011) studies which have found clear relation between stress and obesity. While Nader et al. (2006); Pervanidou and Chrouses (2011); Koski and Naukkarinen (2017) and Honor (2017) have found that stress can causes and fuel and raise obesity risk. Nader et al., (2006) found that children which living in low-income housing are more likely to become obese due to early carbohydrate, low fruits and vegetables intake at $p$-value $=0.05$

life stress. Moore and Cunningham (2012) pointed out that higher stress is associated with less healthy eating behavior, higher body weight and poor nutritional status. Evelyn et al., (2008) noted that obese children may be more prone to mental illness such as depression and selfimpairment than non obese children.

Our study results in table (3) revealed that the majority of pupils $93 \%$ ate grains, $63 \%$ of them ate carbohydrate, while the lowest number of them ate fruits $34 \%$.

The study of Yahya et al., (2005) reported that $60 \%$ of the pupils low consumption of fruits and vegetable and excess sweet intake in 25\%. Gillis and Bar, (2003) compared the eating habits of obese to non-obese children, found that obese children consumed significantly more fast foods than the non-obese children. Chacar and Salameh (2011) found that the children who consumed very high of fried food, soft drinks and chocolate have been linked to higher energy intakes which may increase the risk of developing obesity . In this study high significant relationship was observed at table (4) between stress level and pupils who consumed food high of saturated fat $\mathrm{p}=0.021$, meat $\mathrm{p}=0.000$, carbohydrate $\mathrm{p}=0.01$, and low consumed of fruit $\mathrm{p}=0.000$ and low vegetables $\mathrm{p}=0.03$ at $\mathrm{p}$-value $=0.05$.

The results is agreed with the study of Honor, (2017) which noted that stress has 


\section{Mosul Journal of Nursing, Vol. 7, No. 2, 2019 ( 100-108 )}

been linked with the consumption of food high in fat and sugar. Both Zellner et al. (2007) and Oliver and Wardle (1999) mentioned that all the evidence suggests that stress eating behavior, redirecting food choices to food with greater and energy value or high calories, like sugar and fats. Fernonda et al., (2016) noted that the studies looking at the effect of stress on eating habits have shown that the level of the stressor has an impact on the individuals eating habits, while Pollard et al., (1995) said that there are studies did not find any difference in food compensation as a result of different level of stress .

Most literature has indicated that point to positive associations between the consumption of foods rich in fats and carbohydrates and stress level are common . In the time of stress food choices are redirected to higher palatability food especially those high in sugar and fat (such as sweets) with reduce in the consumption of fresh food such as fruits and vegetables (Zellner et al., 2006; Mikolajczyk et al., 2009 and El-Ansari et al., 2014).

\section{Conclusions}

We believe our study is both necessary and important for children, where we have shown that there is a strong relationship between level of stress and unhealthy dietary intake. children with higher stress level had higher consumption of fast food and snacks which containing a high calories.

\section{Recommendations}

We must pay attention to the child by the family and school, reduce the physiological stress he has by addressing his social problems and enhancing his selfconfidence. Families should take a positive approach to eating, eating more fruits and vegetables and reduce the consumption of high energy dense foods especially fast foods and sweets. Children should get at least one hour of physical activity every day with the possibility of participating in school sports activities according of their wishes.

\section{References}

American heart association (AHA) . (2015) . Saturated fats . https://www.heart.org.

Barnfather , D.,(2004) . Childhood obesity prevention programmes : A study completed for the Auckland Regional, Public Health Service ; 10-17 .

Canfield, J.(2011). Nutrition and stress management Cited in http://www.sites tufts.

Chacar, H.R. and Salameh, P.(2011). Public schools adolescent's obesity and growth Curves in Lebanon, J. Med. Liban. ; 59(2): 80-88.

Charmandari ,E.; Kino, T.; Souvatzoglou, E. and Chrousos ,G.P.(2003). Pediatric stress: Hormonal mediators and human 


\section{Mosul Journal of Nursing, Vol. 7, No. 2, 2019 ( 100-108 )}

development . Horm . Res .; 59(4): 161179.

Davis , M.M. ; Cleveland , B . G . ; Hassink , S. ; Johnson , R. ; Paradis , G . and Resnicow, K. (2007) . Recommendations for prevention of childhood obesity . Pediatrics ; 120 (4) : 229-253 .

Dohrenwend, B.P.(2006). Inventorying stressful life events as risk factors for psychopathology : Toward resolution the problem of intracategory variability ; Psychl Bull ; 132 : 477-495 .

Edelman,C. and Mandle ,C. (1998). Health promotion throughout the life $\operatorname{Span}, 4^{\text {th }}$ Ed., Sanders Co.USA.p:519.

El-Ansari, W. ; Adentunji, H. and Oskrochi, R.(2014). Food and mental health : relationship between food and perceived stress and depressive symptoms among university student's in the United Kingdom . Cent . Eur. J. Public Health ; 22(2):90-97.

Evelyn , P. ; Elizabeth , A.; Selvi , B ., Tracy , L . and Kevin , W . (2008). Effectiveness of weight management programs in children and adolescents. Evidence Report / Technology Assessment; 11-14 .

Fernando, R.O. ; Penaforte ; Nayara, C.M. and Camila, C.J. (2016). Association between stress and eating behavior in college students. Food Nutrition and Health, Demetra ; 11(1):225-237.

Geliebter, A. and Aversa, A.(2003). Emotional eating in overweight, normal weight and underweight individuals. Eat Behav.; 3:341-347

Gillis, L. J . and Bar, O.O. (2003). Food away from home, sugar-sweetened drink consumption and juvenile obesity. Am. Coll. Nutr., 22:539-545.

Honor , Whiteman .( 2017) . Chronic stress may raise obesity risk, Medical news today 2017. https://www.medicalnews today.com.

Hurt, B.I.(2011).Childhood obesity intervention strategies. How do the schools weigh in ? The graduate school University of Wisconsin - stout, Amer Psycho Associ, $6^{\text {th }}$ edition; (30): 6-10 .

Koski , M . and Nankkarinen, H. (2017) . The relationship between stress and sever obesity : A case -control study . Biomed Hub ; 2 : 458771. https://www.doi.org/10.1159 .

Mikolajczyk, R.T. ; Ansari, W.E. and Maxwell , A.E. (2009). Food consumption frequency and perceived stress and depressive symptoms among students in three European countries. Nutr.J. ; 31(8):18.

Moore, C.J , and Cunningham, S.A . (2012). Social position psychological stress and obesity : a systematic review . J Acad. Natr. Diet ; 112:518-526 .

Nader ,P.R.; O'Brien ,M. Houts , R. et al.(2006). Identifying risk for obesity in early childhood. Pediatrics . ;118(3): e594-601

Nelson, C.A.(2013). Biological embedding of early life adversity . JAMA Pediatr.; 167(12):1098-1100 . 


\section{Mosul Journal of Nursing, Vol. 7, No. 2, 2019 ( 100-108 )}

Oellingrath , I.M. ; Svendsen , M.V. and Hestetun, I. (2014). Eating patterns and mental health Problems in early adolescence - a cross sectional study of 12 13 years old Norwegian school children . Public Health Nutr. ; 17(11):2554-2562.

Oliver, G. and Wardle J.(1999).Perceived effects of stress on food choice. Physiol. Behave . ; 66(3):511-515.

Pervanidou , P . and Choruses , G.P . (2011) . Stress and obesity / metabolic syndrome in childhood and adolescence. Int. J. Pediatr. obes. ; 6 (suppl 1) :21-28 .

Pollard, T.M. ; Steptoe, A. ; Canaan , L. ; Davies, G.L. and Wardle, J. (1995). Effects of academic examination stress on eating behavior and blood lipid levels . Int. J. Behav. Med .22:299-320.

Sally , Robertson . (2018). Obesity and stress .News medical life science, Top online MBA, UNICAF Scholarships . Aug. $23 \quad, \quad 2018$. https://www.Newsmedical.net .

Steptoe, A. ; Lipsey, Z . and Wardle , J .(1998) . Stress, hassles, and variations in alcohol consumption, food choice, and physical exercise ; A diary study . Br. J. Health Psychol . ; 3:51-63 .

Tamashiro , K.L . (2011), Metabolic syndrome-links to social stress and socioeconomic status . Ann. NY Acad. Sci., 1231:46-55 .

Telma ,R. ; Yang, X. ; Leskinen ,E. et al .(2014). Tracking of physical activity from early childhood through youth into adulthood . Med .Sci . Sports Exeyc.; 46(5): 955-962.
Torres, S and Nowson, C.(2007). Relationship between stress, eating behavior and obesity . Nutrition; 23(1112):887-894.

Triches , R.M. and Giuglianb , E.R., (2005) ; Obesity , eating habits , and nutritional knowledge among school children , Rev . Saude Publica , 39 (4) :1-7

Tsenkova,V.; Boylan, J. M. and Ryff, C.(2013). Stress eating and health. Findings from MIDUS, a national study of US adults. ;66:151-155.

WHO , World Health Organization . (2000) , Obesity : Preventing and managing the global epidemic . Technical Report. WHO : Geneva 2000 ; (894). WHO, World Health Organization . (2017). Mental Health : Mental disorders. Available at http://www. WHO. Int / mental health / management/en/.

WHO, World Health Organization. (1985)

: Assessment socio-economic status of family , WHO Report , Geneva , Switzerland ; 51 .

Yahya, Bayda A .; Abdul-lattef, Suha J . and Ahmed, Sana T., (2005) . Assessment of nutritional status of primary schools pupils in Mosul City ., Mesopotamia J. of Agric.Vol (33), No:(4):31-38.

Zellner, D.A. ; Saito, S. and Gonzalez ,J. (2007). The effect of stress men's food selection . , 49(3):696-699.

Zellner, D.A. ; Loaiza, S. ; Gonzalez, Z. ; Pita, J. ; Morales , J. ; Pecora, D. ; et . al . (2006). Food selection changes under stress. Physiol. Behave .; 87(4):789-793 